\title{
Jet reveals atmosphere's secrets
}

\section{Marathon flights test models with first pole-to-pole snapshot of trace gases.}

If only they could cash in the air miles. By flying nearly 50,000 kilometres between the Arctic Ocean and the Antarctic coast and repeatedly sampling the air at a broad range of altitudes, scientists are building the most detailed profile of the atmosphere yet.

In spring this year, during its third of five planned missions, a specially outfitted Gulfstream V jet, owned by the US National Science Foundation and operated by the National Center for Atmospheric Research in Boulder, Colorado, journeyed northwards, nearly reaching the Pole before turning south towards the Antarctic. The plane made occasional refuelling stops along the way, and then largely retraced its eastern Pacific route before returning to its home base (see map). As it flew, the plane (formerly known as HIAPER - the High-Performance Instrumented Airborne Platform for Environmental Research) repeatedly climbed as high as 13.7 kilometres and dipped down to a nail-biting 150 metres above the ocean waves, all the while sampling more than 100 atmospheric constituents, including greenhouse gases, aerosols and a suite of natural and industrial chemicals.

Now, early results from that flight and two previous ones with the same aircraft, presented on 9 August at a joint assembly of the American Geophysical Union and several Latin American societies in Iguaçu Falls, Brazil, are yielding surprises in the distribution of trace gases and airborne pollution.

Scientists generally have to rely on ground measurements and then use mathematical models to extrapolate upwards when they need to create a picture of the global atmosphere, says Steve Wofsy, an atmospheric researcher

\section{INCREDIBLE JOURNEY}

On its third of five planned flights, the HIPPO team sampled the atmosphere from the Arctic to Antarctica.
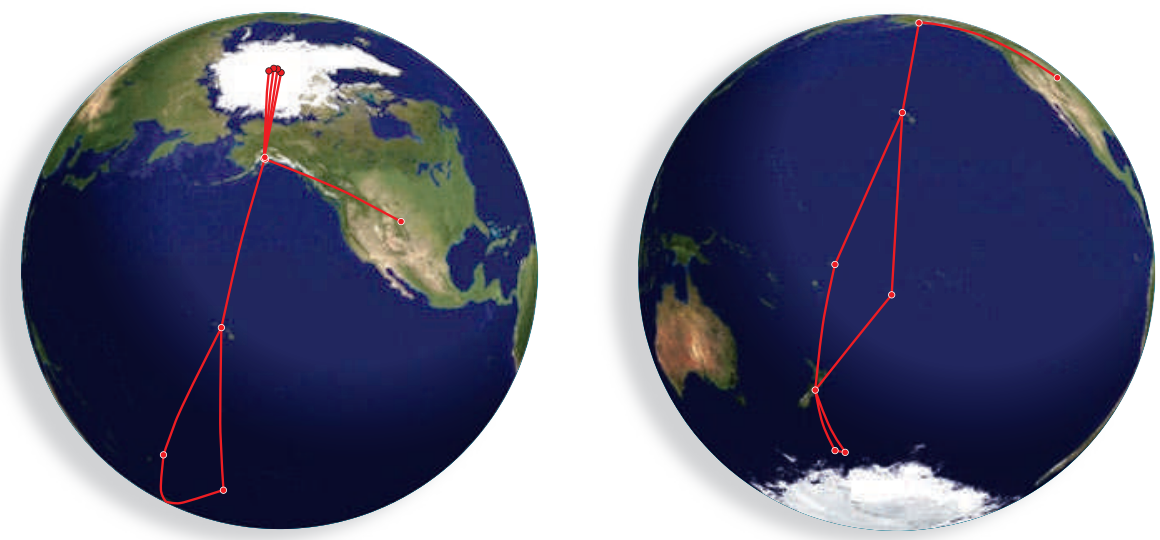

at Harvard University in Cambridge, Massachusetts, and the principal investigator for the US\$4-million HIAPER Pole-to-Pole Observations (HIPPO) project. "That's like studying the ocean by studying what is on the surface of the ocean," he says. In contrast, HIPPO can help modellers to test their ability to reproduce the atmosphere in three dimensions.

Among the surprises to come out of HIPPO data are nitrous oxide concentrations that consistently seem to increase with altitude. "Yet the models all show concentrations decreasing with altitude," says Wofsy. The implication, he adds, is that models are either not properly accounting for the transport of nitrous oxide or they are missing a source of the greenhouse gas.

The HIPPO team also found that black carbon particles originating in Asia and beyond

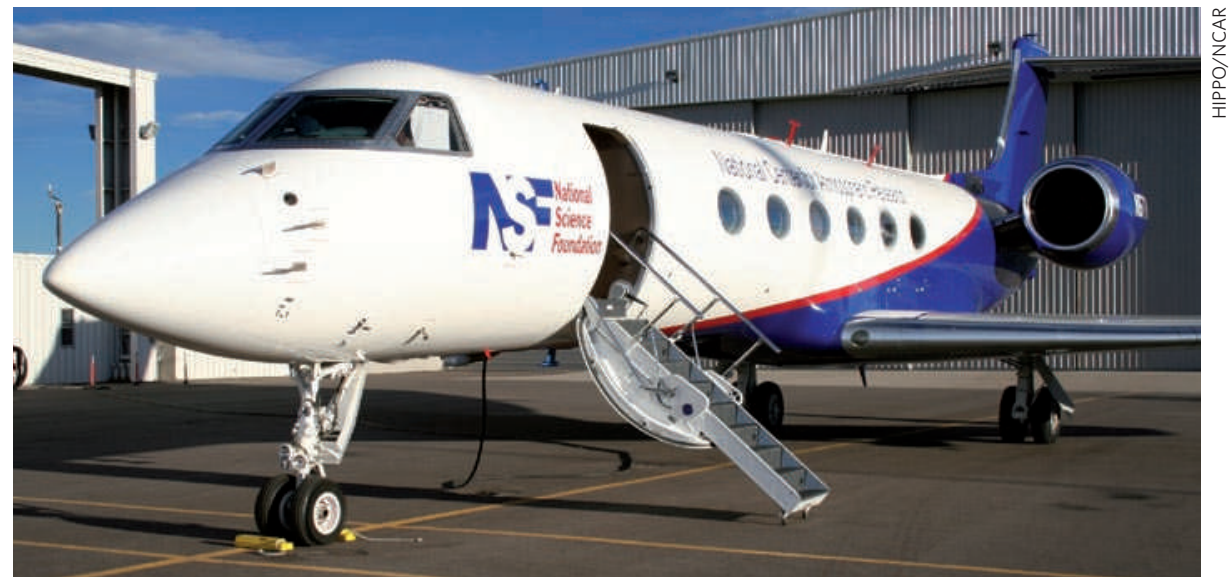

Researchers have been using instruments on this adapted Gulfstream $V$ jet to profile Earth's atmosphere.

taper off much more quickly than expected over the Pacific. Wofsy and his colleagues report that the first HIPPO flight in January 2009 found levels of black carbon that average about five times lower than predicted by an ensemble of 14 global aerosol models (J. P. Schwarz et al. Geophys. Res. Lett. doi:10.1029/2010GL044372, in the press). The models underestimated how much black carbon is being scrubbed out of the air by precipitation, says lead author Joshua Schwarz, an atmospheric scientist with the National Oceanic and Atmospheric Administration (NOAA) in Boulder.

Prabir Patra, a climate modeller at the Japanese Agency for Marine-Earth Science and Technology in Yokohama who is already working with Wofsy, says that the HIPPO data will serve as a valuable new resource. By tracing various constituents in the database back to their likely sources, he says, modellers should be able to glean information about circulation trends and then improve the way their models represent the atmosphere.

Germany is currently developing a similar aircraft called the High Altitude and Long Range Research Aircraft, or HALO, which is expected to fly a parallel mission over the Atlantic Ocean in the coming years.

For Wofsy, who gave up his seat to make room for NOAA's laser-based black-carbon counter, the flights are bittersweet. Nevertheless, he has been up in the air for a few flights and has experienced the thrill of skimming over the waves at 150 metres, watching seals on ice floes as the jet whooshes past. "We want to see penguins," he says, "but we haven't seen any yet." Jeff Tollefson 